\title{
Transapical transcatheter valve-in-ring implantation for failed mitral valve repair in the absence of radiopaque markers
}

\author{
Manuel Wilbring, MD, Utz Kappert, MD, PhD, and Klaus Matschke, MD, PhD
}

Transcatheter heart valve procedures have continuously expanded their fields of application, recently also including valve-in-valve transcatheter aortic valve implantation (TAVI) for failed aortic or mitral bioprostheses. ${ }^{1,2}$ As a new pattern, successful valve-in-ring TAVI procedures for failed mitral repair have also recently been published. ${ }^{3}$ The transapical approach provides a direct and coaxial access to the aortic or mitral valve, and the radiopaque markers of the degenerated bioprostheses or annuloplasty rings usually clearly indicate the correct landing zone. Both of these features make valve-in-valve or valve-in-ring procedures both easy and convenient to perform-nearly like a penalty shot without a goal keeper. But what is one to do if there are no radiopaque structures?

\section{CLINICAL SUMMARY}

We report the case of an 83-year-old woman with a history of mitral and tricuspid valve repair 9 years previously who was seen with severe mitral regurgitation as a consequence of chordal rupture (Figure 1, A). The heart team chose a catheter-based approach because of her prohibitive surgical risk, as represented by a calculated Society of Thoracic Surgeons Predicted Risk of Mortality score of $13.8 \%$. Relevant baseline characteristics included insulin-dependent diabetes, chronic obstructive pulmonary disease being treated with a regimen of corticosteroids, chronic kidney disease, peripheral vascular disease, and alimentary adipositas with a body mass index of $35.9 \mathrm{~kg} / \mathrm{m}^{2}$. Notably, previous mitral repair had been performed with a $28-\mathrm{mm}$ St Jude Medical Seguin annuloplasty ring (St Jude Medical, Inc, St Paul, Minn), which unfortunately was characterized by the absence of radiopaque markers.

The patient then underwent valve-in-ring TAVI. By means of the circle formula, diameter $=2 \times \sqrt{ }(\operatorname{area} / \pi)$,

From the Department of Cardiac Surgery, University Heart Center Dresden, Dresden, Germany.

Disclosures: Authors have nothing to disclose with regard to commercial support. Received for publication Dec 14, 2014; revisions received March 23, 2015; accepted for publication March 26, 2015; available ahead of print March 11, 2015.

Address for reprints: Manuel Wilbring, MD, University Heart Center Dresden, Fetscherstrasse 76, 01307 Dresden, Germany (E-mail: manuel.wilbring@gmail.com). J Thorac Cardiovasc Surg 2015;149:e92-4

$0022-5223 / \$ 36.00$

Copyright (c) 2015 by The American Association for Thoracic Surgery

http://dx.doi.org/10.1016/j.jtcvs.2015.01.068 we calculated from the ring area given by the manufacturer the estimated diameter of the ring after circularization during the implantation procedure. ${ }^{3}$ On the basis of this calculation, we selected a 26-mm Edwards SAPIEN XT bioprosthesis (Edwards Lifesciences Corporation, Irvine, Calif). The procedure was performed through a transapical approach, which allowed a direct and coaxial access to the mitral valve. After placement of the apical purse-string sutures, a stiff wire was placed in the right upper pulmonary vein, targeted to provide a favorable angle to the mitral valve. Neither prefatory balloon valvuloplasty nor use of a contrast agent was performed. Subsequently, the delivery device was inserted, and the valve was slowly brought stepwise into position. We aimed for a centered position of the SAPIEN XT valve in the mitral ring with equal proportions in the left ventricle and left atrium. Because of the lack of radiopaque markers of the St Jude Medical Seguin annuloplasty-ring (Figure 1, B), the implantation procedure was exclusively guided by transesophageal echocardiography (Figure 1,C). During this procedure, standard angiography was not helpful. For guidance and visualization of the valve and mitral ring, a Philips iE33 with a $x 7-2 t$ probe providing the Live 3D Echo feature (Philips Healthcare, Hamburg, Germany) was used. The final positioning of the valve in the center of the ring was performed with both 2-dimensional and the Live 3D transesophageal echocardiographic imaging. Once the valve was in the exact final position, deployment of the 26-mm Edwards SAPIEN XT bioprosthesis was slowly and gradually performed under continuous transesophageal echocardiographic imaging control.

The final results were satisfactory, with excellent prosthesis function and only trace paravalvular regurgitation (Figure 1, $D$ and $E$ ). The patient's further postoperative course was uneventful. Follow-up examination by standard 2-dimensional echocardiography 1 year after surgery revealed constant prosthesis function. The patient likewise remained in good clinical condition and showed no evidence of cardiac-related morbidity during the followup period.

\section{DISCUSSION}

Transcatheter heart valve procedures for failed bioprostheses in the aortic or mitral position have advanced to become a viable option for even the highest risk patients. ${ }^{1,2,4}$ The presence of radiopaque markers usually 


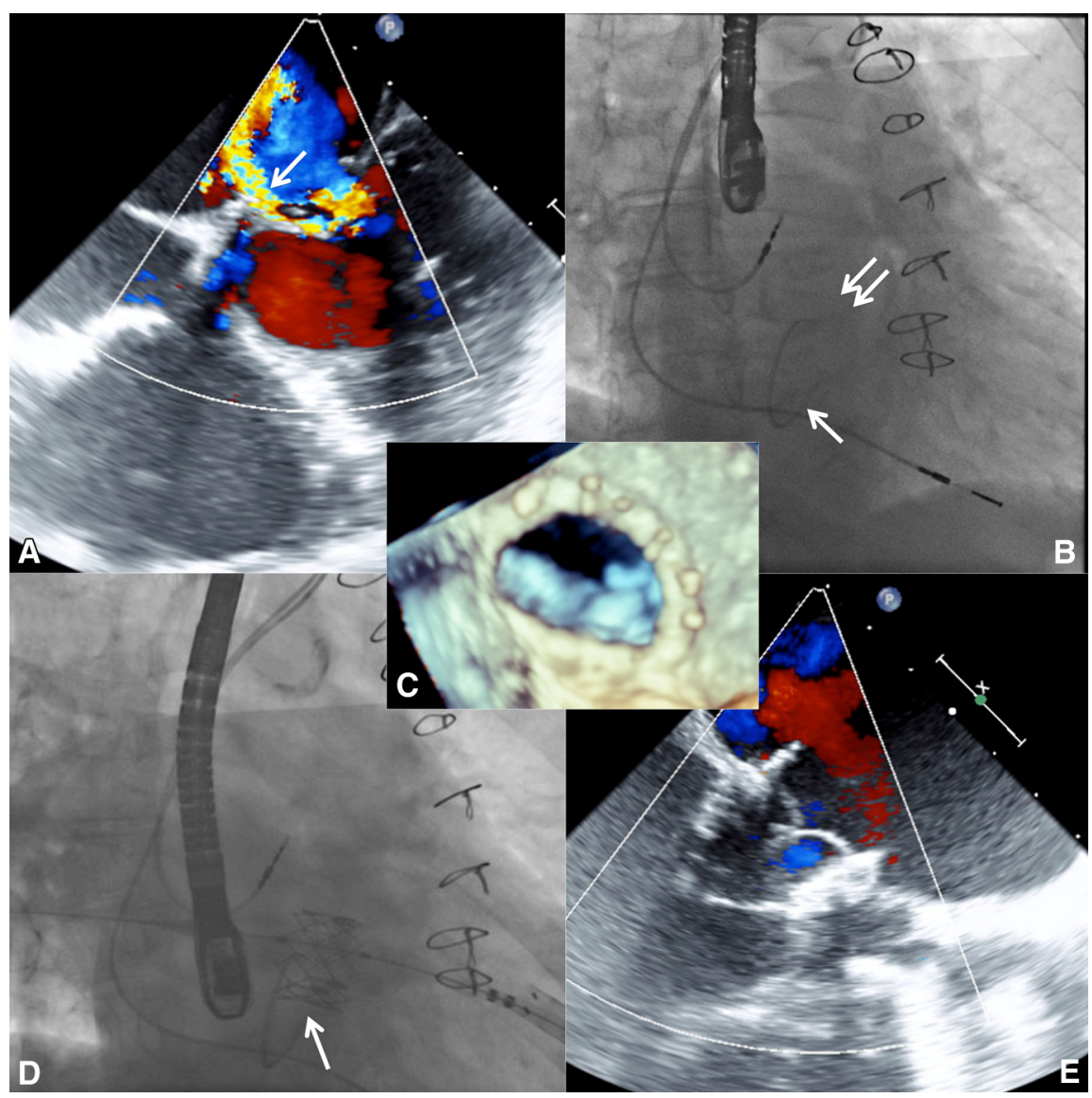

FIGURE 1. A, Failed mitral repair with severe mitral regurgitation as a consequence of chordal rupture. B, Fluoroscopy was unhelpful, because the previous mitral repair had been performed with a radiolucent 28-mm St Jude Medical Seguin annuloplasty-ring (double arrows). Fluoroscopy revealed only the tricuspid annuloplasty ring (single arrow). C, The mitral ring was identified as a landing zone with 3-dimensional echocardiography. D, Successful transapical valve-in-ring transcatheter aortic valve implantation was performed. E, Final postoperative echocardiography revealed a satisfactory result, with excellent prosthesis function and only trace paravalvular regurgitation.

clearly delineates a clear landing zone..$^{1-3}$ In addition, the stent scaffold of the degenerated bioprosthesis or the annuloplasty ring provides a stable landing zone, preventing the compression of the surrounding tissue. ${ }^{1-3}$

A particular problem arises in a high-risk patient who has had a failed mitral valve repair that was performed with an annuloplasty ring lacking radiopaque makers. In this configuration, the usually essential fluoroscopy becomes unhelpful for guidance and positioning of the transcatheter heart valve.

In our case, we decided instead to use echocardiography as our primary guidance. Alternative strategies have been reported in this setting. These include the use of radiopaque suture devices such as the COR-KNOT system (LSI Solutions, Inc, Victor, NY) during the primary surgery and the delineation of a radiolucent ring during the valve-in-ring surgery by deploying a contrast-filled balloon.

For the purpose of determining valve placement and orientation, we tried to use all available data sources, including both 2-dimensional and 3-dimensional echocardiographic information. The third dimension and the possibility of rotating the (reconstructed) view allowed proper alignment of the valve in the center of the annuloplasty ring. Displaying the whole scene with the top and bottom of the valve and the annuloplasty ring remains difficult. Furthermore, the alignment has to be guided and checked in different views. Finally, during the valve deployment a certain shakiness cannot be fully excluded. This proceeding on the one hand allows mitral valve-in-ring procedures in the absence of radiopaque annuloplasty rings but on the other hand cannot be as exact as a conventional procedure guided by fluoroscopy.

The margin of safety is thus narrowed. A defined, welltrained, and well-rehearsed TAVI team becomes more essential. Basic demands particularly include an anesthetist who is well experienced with echocardiography, as well as intimate communication between the operating surgeon and the whole TAVI team. A central aspect of the procedure is 
the pattern of communication and cooperation between the echocardiographic anesthetist and the surgeon-both proverbially have to act like a single person.

\section{References}

1. Wilbring M, Sill B, Tugtekin SM, Alexiou K, Simonis G, Matschke K, et al. Transcatheter valve-in-valve implantation for deteriorated aortic bioprosthesis: initial clinical results and follow-up in a series of high-risk patients. Ann Thorac Surg. 2012;93:734-41.
2. Wilbring M, Alexiou K, Tugtekin SM, Sill B, Hammer P, Schmidt T, et al. Transapical transcatheter valve-in-valve implantation for deteriorated mitral valve bioprostheses. Ann Thorac Surg. 2013;95:111-7.

3. Wilbring M, Alexiou K, Tugtekin SM, Arzt S, Ibrahim K, Matschke K, et al. Pushing the limits - further evolutions of transcatheter valve procedures in the mitral position, including valve-in-valve, valve-in-ring, and valve-in-native-ring. $J$ Thorac Cardiovasc Surg. 2014;147:210-9.

4. Dvir D, Webb JG, Bleiziffer S, Pasic M, Waksman R, Kodali S, et al; Valve-in-Valve International Data Registry Investigators. Transcatheter aortic valve implantation in failed bioprosthetic surgical valves. JAMA. 2014;312: 162-70.

\title{
Safe sternal reentry in the setting of a giant aortic pseudoaneurysm and aortic regurgitation
}

\author{
Brody Wehman, MD, Brian McCormick, CPP, Si Pham, MD, and Bradley S. Taylor, MD, MPH, \\ Baltimore, Md
}

See related commentary on pages e96-7.

A rare but potentially devastating complication of aortic surgery is the development of a large pseudoaneurysm, which results from dehiscence of a previously placed aortic graft from 1 or both suture lines. ${ }^{1,2}$ Critical to a successful outcome in this scenario is a strategy that will prevent catastrophic hemorrhage and ensure cerebral protection should the pseudoaneurysm be directly entered during sternal reentry, which may be unavoidable depending on its size and location. ${ }^{3}$ When clinically significant aortic regurgitation is present, adequate measures to prevent left ventricular (LV) distention must be factored into the setup of cardiopulmonary bypass (CPB) and operative planning. The purpose of this report is to describe a complex aortic case that encompassed these considerations in the surgical approach.

\section{CASE REPORT}

A 66-year-old man with a previously repaired type A dissection presented with worsening shortness of breath

From the Division of Cardiac Surgery, University of Maryland Medical Center, Baltimore, Md.

Received for publication Dec 15, 2014; revisions received Jan 18, 2015; accepted for publication Jan 29, 2015; available ahead of print March 11, 2015

Address for reprints: Brody Wehman, MD, Division of Cardiac Surgery, University of Maryland Medical Center, 110 S. Paca St, 7th Floor, Baltimore, MD 21201 (E-mail: BWEHMAN@smail.umaryland.edu).

J Thorac Cardiovasc Surg 2015;149:e94-6

$0022-5223 / \$ 36.00$

Copyright (c) 2015 by The American Association for Thoracic Surgery

http://dx.doi.org/10.1016/j.jtcvs.2015.01.068 alleviated by lying on his right side. Computed tomography of the chest revealed a giant ascending aortic pseudoaneurysm compressing the right pulmonary artery and vein secondary to dehiscence of the aortic graft from the proximal and distal anastomoses (Figure 1). Moderate-to-severe aortic regurgitation was demonstrated by transthoracic echocardiogram. Shortly after admission, respiratory and acute renal failure developed in the patient.

The patient was taken urgently to the operating room to remove the previous aortic graft and reconstruct the thoracic aorta. The patient was peripherally cannulated for CPB via the axillary artery and femoral vein. A left anterolateral thoracotomy was then made, and the fourth intercostal space was entered. The LV apex was visualized, and pledgeted sutures were placed to secure an LV vent. Bilateral carotid artery cannulation was then performed via cervical cut-down to allow for selective antegrade cerebral perfusion, which was achieved using $14 \mathrm{~F}$ pediatric cannulas (Figure 2) ${ }^{3,4}$ Flow rates of $750 \mathrm{~mL}$ to $1.0 \mathrm{~L} / \mathrm{min}$ at $9^{\circ} \mathrm{C}$ were achieved, and the carotid arteries were clamped proximal to the cannulation sites, which served to protect the brain from air embolism in the event of entry into the pseudoaneurysm during sternal reentry. Inflow of normothermic blood from the LV sump did not affect pump outflow temperature to the carotid arteries. Electroencephalographic quiescence was observed before sternal entry and throughout the case.

The patient was cooled to $34^{\circ} \mathrm{C}$, and the sternum was entered 140 minutes into the operation. During sternal reentry, CPB flow was temporarily reduced from full flow $(5.5 \mathrm{~L} / \mathrm{min})$ to partial flow $(3.6 \mathrm{~L} / \mathrm{min})$. Re- 